\title{
An Adolescent with a Phyllodes Tumor: A Case Report and Review of Literature
}

\author{
Maha Oudrhiri*, Houda Oubejja, Fouad Ettayebi, Hicham Zerhouni \\ Department of pediatric surgical emergencies of Rabat Children's Hospital, Faculty of Medicine and Pharmacy, \\ Mohamed V University, Rabat, Morocco
}

\begin{abstract}
*Corresponding Author: Maha Oudrhiri, Department of pediatric surgical emergencies of Rabat Children's Hospital, Faculty of Medicine and Pharmacy, Mohamed V University, Rabat, Morocco, E-mail: oudrhiri.md.phd@gmail.com
\end{abstract}

\begin{abstract}
Phyllodes tumors are rare fibroepithelial tumors that represents 0.3 to $0.9 \%$ of breast tumors in woman. Presentation in young girls is even rarer. In this paper, we describe a case of an adolescent with a phyllodes tumor. The rare presentation at this age, its distinguishing features, the preoperative diagnostic difficulties, and the management protocols of this uncommon tumor are highlighted.
\end{abstract}

Keywords: phyllode tumor, tumor of the breast, child, surgery.

\section{INTRODUCTION}

The phyllodes tumors of the breast constitute a particular entity in the mammary pathology: they represent less than $1 \%$ of all the tumors of breast. They are rarely seen in adolescents, with only about ten cases reported [1].Here we report a case of a child with a right breast mass that histopathology of the operative specimen revealed to be a benign phyllode tumor.

\section{OBSERVATION}

We report the observation of a 12-year-old girl, admitted to right breast mass. Having as a family antecedent a maternal aunt operated for breast neoplasia.

The beginning of the symptomatology dates back to 3 months ago by the self-examination of a firm mass slightly painful in the right breast, gradually increasing in volume, which motivated a consultation

The examination found a swollen right breast with inflammatory signs opposite a palpated mass at the junction of the two upper mobile quadrants measuring $5.5 \mathrm{~cm}$ in diameter without ipsilateral lymphadenopathy (Figure 1).

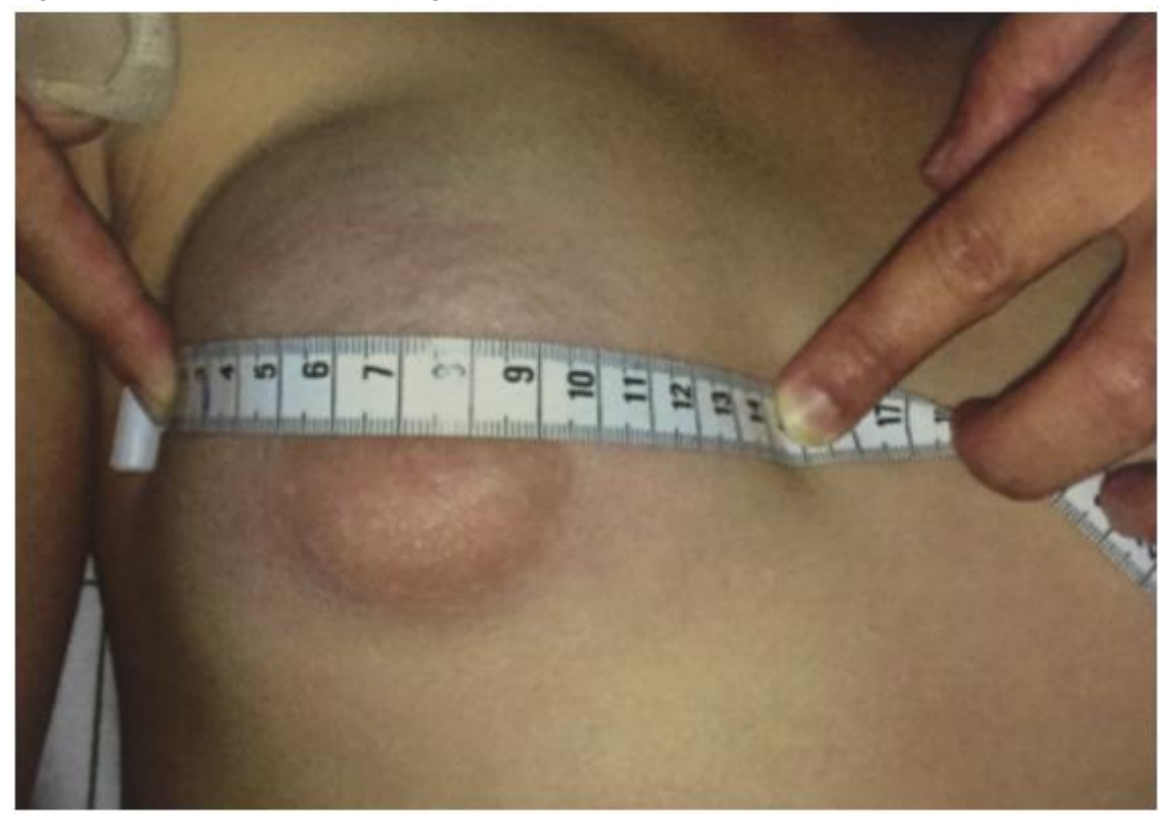

Figure1. Right breast mass with inflammatory sign 
Breast ultrasound revealed a tumoral process occupating almost the entire right breast, very heterogeneous micro-lobulated irregular contours containing venous lakes measuring 84 * $60 \mathrm{~mm}$, aspect in favor of a phyllode tumor probably high grade. A microbiopsy was performed in favor of a juvenile fibroadenoma the evolution was marked by the significant increase of the volume of the mass after the refusal of the patient of the surgical treatment (figure 2).

A second biopsy done 4 months later in favor of a phyllode tumor of intermediate grade

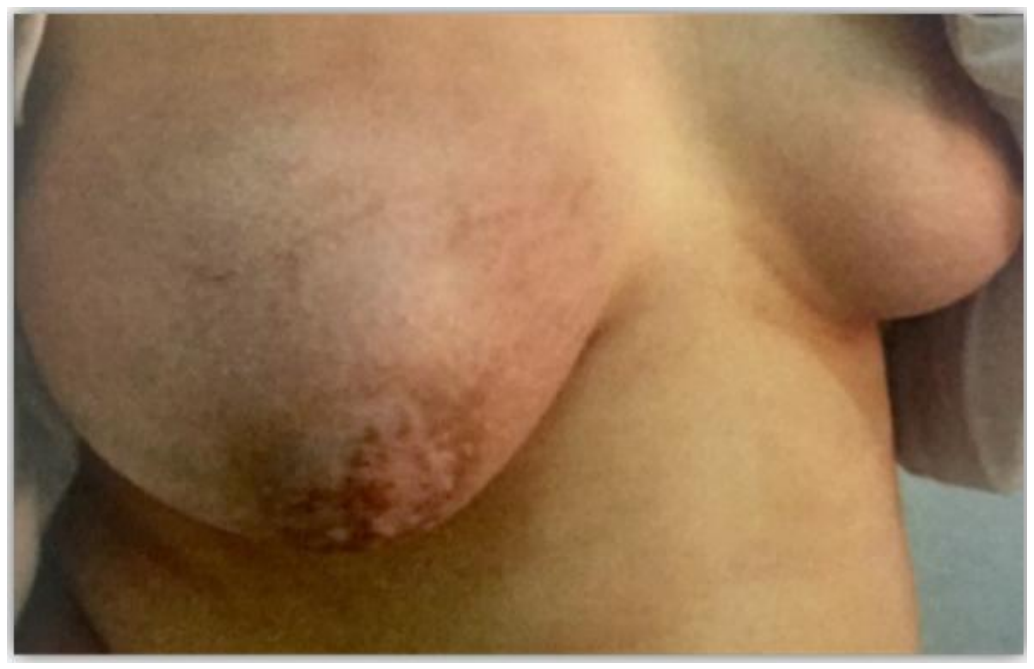

Figure2. Increase in the volume of the mass after 3 months

The patient underwent a right mastectomy because of the volume of the tumor (figure3) whose anatomopathological study is compatible with a benign phyllode tumor of grade I.

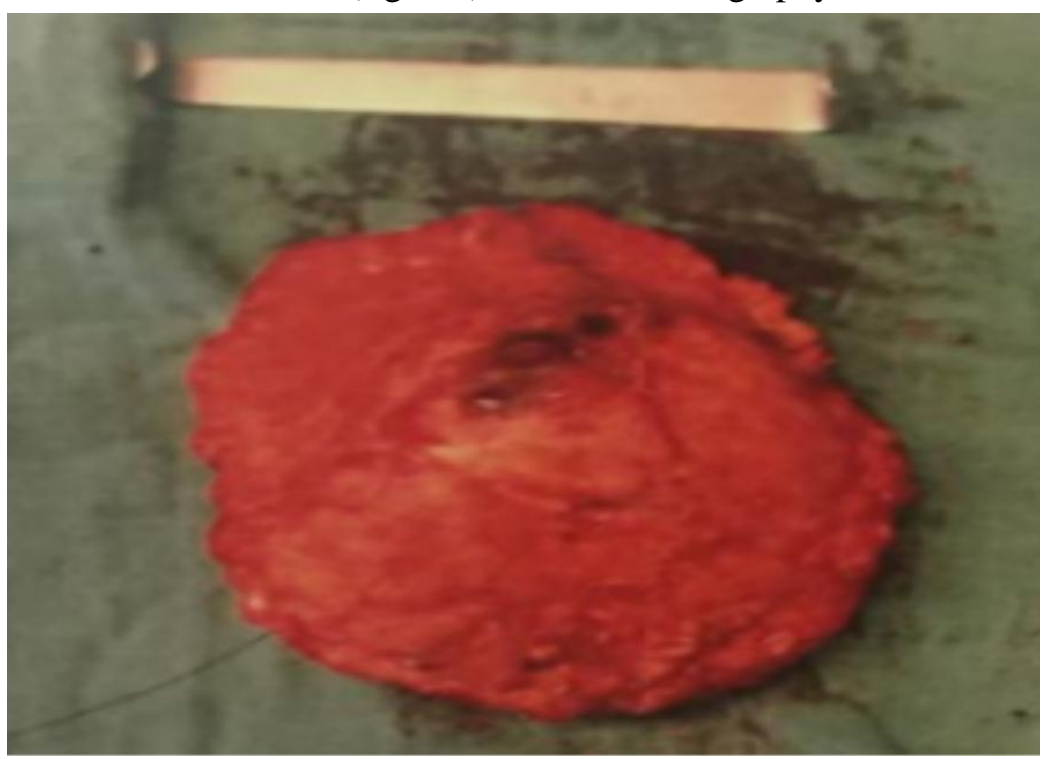

Figure3. Mastectomy specimen

\section{DISCUSSION}

Malignant breast pathology in children and adolescents occurs in less than $0.9 \%$ of cases, leading to a different breast mass than in adult women.Pediatric mammary masses of tumoral origin are generally benign and $95 \%$ of the cases are benign fibroadenomas [2].

Phyllode tumors of the breast are fibroepithelial tumors similar to fibroadenomas, but with a predominant component of connective tissue, a greater frequency of recurrence and sometimes malignant evolution. They classically have a foliated structure in the cup, hence their phyllode name (in Greek phyllos means leaf) (3). Phyllodes tumors are distinguished benign tumors, intermediate malignancy or malignant.

They can be met at any age, but the median age is the fifth decade of life. Her teenage onset is rare. Only $8 \%$ occur in children under 20 years old. The youngest age in the literature is 10 years old (4). 
Since their first description, by Johanne Muller in 1938, phyllodes tumors remain a subject of controversy as to their terminology, their histological classification, their treatment and their evolutionary character.

Fibroadenomas and phyllodes tumors share many common features. Clinically, they present themselves as rounded, circumscribed and mobile masses. Histologically, both can be grouped into "fibroepithelial lesions".

Preoperative diagnosis is difficult to diagnose because of the fine needle aspiration and central needle biopsy may not be able to distinguish a phyllode tumor from a fibroadenoma.

Indeed, only the anatomo-pathological analysis of the whole of the operative part makes it possible, on the condition of an abundant sampling, to specify the diagnosis and its histopronosis.

All clinical studies recommend performing an enlarged lumpectomy with a minimum margin of safety of $10 \mathrm{~mm}$ to prevent recurrence (5). Enucleation is proscribed [6]. The realization of a mastectomy is indicated for tumors larger than $5 \mathrm{~cm}$, and grade 3 .

All phyllodes mammary tumors, whatever their grade, may re-induce locally and all have a metastatic potential [7]. Recurrence occurs two to three years after surgical excision [3]

\section{CONClusion}

The phyllodes tumors of the child and the teenager are very rare ones.

Our observation illustrates the difficulties of differential diagnosis of this type of tumor whose basic treatment at present is dominated by surgery.

\section{REFERENCES}

[1] B. Erginel, B. Celet Ozden, S. Yesil Onder, S. Yuksel, F. Gun Soysal, A. Celik, et al. Management of a benign phyllodes tumor in a 13-year-old girl with trans-position of the nipple areola complex and breast reconstruction Acta Chir Belg, 115 (3) (2015 May-Jun), pp. 256-259.

[2] Makhija, D., Shah, H., Bothra, J., \& Jayaswal, S. (2016). An adolescent with a phyllodes tumor: A case report and review. International Journal of Pediatrics and Adolescent Medicine, 3(4), 180-183.

[3] Bouhafa, T., Masbah, O., Bekkouch, I., Afqir, S., Mellas, N., Ismaili, N., ... \& Errihani, H. (2009). Tumeurs phyllodes du sein a propos de 53 cas. Cancer/Radiothérapie, 13(2), 85-91.

[4] Boisserie-Lacroix, M., Lippa, N., Ferron, S., Hurtevent-Labrot, G., \& Bullier, B. (2013). Pathologie mammaire de l'adolescente et de la jeune fille. Imagerie de la Femme, 23(2), 70-75.

[5] Cecen, E., Uysal, K. M., Harmancioglu, O., Balc1, P., Kupelioglu, A., \& Canda, T. (2008). Phyllodes tumor of the breast in an adolescent girl. Pediatric hematology and oncology, 25(1), 79-82.

[6] Sabban, F., Collinet, P., Lucot, J. P., Boman, F., Leroy, J. L., \& Vinatier, D. (2005). Tumeurs phyllodes du sein: À propos de 8 patientes. Journal de gynécologie obstétrique et biologie de la reproduction, 34(3), 252-256.

[7] Guerrero MA, Ballard BR, Grau AM. Malignant phyllodes tumor of the breast: review of the literature and case report of stromal overgrowth. Surg Oncol 2003; 12:27-37.

Citation: Maha Oudrhiri, et al,. An Adolescent with a Phyllodes Tumor: A Case Report and Review of Literature. ARC Journal of Pediatrics.2019; 5(1):1-3. doi:dx.doi.org/10.20431/2455-5711.0502001.

Copyright: (C) 2019 Authors. This is an open-access article distributed under the terms of the Creative Commons Attribution License, which permits unrestricted use, distribution, and reproduction in any medium, provided the original author and source are credited. 